\title{
TECNOLOGIAS E O CONHECIMENTO PEDAGÓGICO NA FORMAÇÃO DO LICENCIANDO EM QUÍMICA NA MODALIDADE EM EAD
}

\author{
SANTOS/SP MAIO/2018
}

\author{
Ana Lúcia de Braga e Silva Santos ～- UNIMES - analu.braga@hotmail.com \\ Érika Coelho D’Anton Reiper - UNIMES - erika.reipert@unimes.br
}

Tipo: Relato de Experiência Inovadora (EI)

Categoria: Métodos e Tecnologias

Setor Educacional: EDUCAÇÃO SUPERIOR

\begin{abstract}
RESUMO
A função do professor está em constante evolução e, por isso, é preciso estar apto às modificações que ocorrem no decorrer de carreira. Para que a aprendizagem ocorra de forma satisfatória é essencial que o professor tenha conhecimento pleno do conteúdo específico, bem como o conhecimento da prática pedagógica para trabalhar tais conteúdos. Vivemos em um mundo de mudanças constantes e velozes, assim, a forma de utilizar as novas tecnologias como integrantes do processo ensinoaprendizagem se torna um desafio para os professores de todas as áreas do conhecimento. Neste estudo, abordamos estes dois pontos, através da apresentação de uma atividade que foi desenvolvida em um curso de licenciatura em química no qual propusemos a utilização de dois objetos digitais de aprendizagem e a análise pedagógica destes.
\end{abstract}

Palavras-chave: Educação Química. Conhecimento pedagógico. Objetos Digitais de Aprendizagem. 


\section{Introdução}

A reflexão sobre a educação formal faz parte de diversos estudos e apresentam sua importância uma vez que dela advém o futuro das gerações. Os inúmeros recursos tecnológicos já se encontram disponíveis em diversas instituições públicas e privadas e devem se fazer presentes no processo de ensino-aprendizagem. Como fazer esta prática uma constante e como formar professores capazes de utilizar as tecnologias como integrantes do processo de ensino aprendizagem é um desafio.

Para a geração de professores que estão sendo formados seria esperada uma facilidade em utilizar esses recursos, mas isto não é uma realidade, uma vez que não a tecnologia raramente fez parte de sua formação escolar. Sendo consolidado apenas na sua formação universitária.

Esse é o cerne do problema quando se trata de uso (ou, mais precisamente, do desuso) das tecnologias nas escolas, a despeito de todo o investimento público: a formação inicial e continuada do professor. Dentre tantas questões relacionadas a essa problemática, é fundamental refletir sobre as práticas, os métodos e as didáticas específicas para uso das TDIC nas licenciaturas. (SOUZA, 2016. p. 420).

Políticas públicas para a inclusão de tecnologias nas escolas de educação básica estão cada vez mais constantes e os professores têm que se preparar para esta realidade. É papel da universidade auxiliar os profissionais a se sentirem aptos na escolha da melhor tecnologia, observando as especificidades de cada conteúdo e orientar que tão importante quanto a escolha é a determinação dos objetivos que se quer alcançar com o recurso. A utilização das tecnologias tem que estar atrelada aos objetivos. O que se verifica muitas vezes é a utilização de vídeos, laboratórios de informática, celulares, entre outros, pelo simples fato de apresentarem algo diferente aos alunos, mas sem a preocupação de que estes recursos atendam aos objetivos esperados, não sendo utilizados criteriosamente.

[...] professores que conhecem não somente uma grande variedade de métodos de ensino, mas também de teorias de aprendizagem e seus fundamentos epistemológicos, estão em uma posição muito melhor para tomar decisões adequadas sobre como ensinar em um contexto particular. (BATES, 2016. p. 158).

Ribeiro aborda a questão a partir de um exemplo sobre uma resolução matemática incorreta destacando que:

[...] qualquer um que pode resolver o problema anterior poderá verificar um resultado incorreto. Não obstante, ensinar envolve mais do que identificar uma resposta incorreta, pois requer capacidade de dimensionar a fonte do erro matemático. [...]. Contudo, essa tarefa, no ensino, difere somente pelo fato de que o foco de análise são os erros produzidos por outros, pelos alunos. (RIBEIRO, 2012. p. 540). 
Neste ponto, faz-se necessário o trabalho acadêmico com os futuros profissionais em educação. É fundamental quebrar o paradigma de uma educação segmentada e fundamentada no ensino compartimentado e estanque.

Figueiredo destaca que os alunos tendem a manter as concepções e experiências anteriores utilizando-as no seu processo de ensino-aprendizagem.

Para Shulman (2014) a formação acadêmica deve abordar de forma consolidada o estudo da prática pedagógica que a classifica como conhecimento pedagógico do conteúdo.

\section{Objetivos}

Diante da falta de consolidação da utilização de novas tecnologias nas aulas do ensino médio sentiu-se a necessidade de se trabalhar a utilização de Objetos Digitais de Aprendizagem (ODAs) na formação de professores. Assim, o presente trabalho tem como objetivo apresentar uma abordagem de introdução de novas tecnologias na futura prática docente de licenciandos em química.

\section{Referencial Teórico}

A formação acadêmica de um professor tem que estar respaldada não somente pelo conhecimento específico do conteúdo e a área que este vai lecionar, mas abordar também o conhecimento necessário para ensinar tal conteúdo. Cada área necessita de diferentes habilidades que atendem as suas especificidades. Muitas vezes, mesmo pessoas que não são fluentes em determinado conteúdo percebem que uma questão está incorreta, mas, é preciso uma formação específica para saber demonstrar e explicar como resolver a questão de forma correta.

Os estudos de Shulman são de grande importância para este trabalho uma vez que o conhecimento para a docência é nosso foco. A formação voltada para o ensino e a aprendizagem é essencial, tanto quanto o conhecimento aprofundado do conteúdo específico. O professor tem que estar preparado para desenvolver uma questão de diferentes modos, pois, os alunos podem apresentar diferentes formas de conhecimentos que atendam os mesmos fins, bem como, a forma como ensinar o conteúdo.

Um professor pode transformar a compreensão de um conteúdo, habilidades didáticas ou valores em ações e representações pedagógicas. Essas ações e representações se traduzem em jeitos de falar, mostrar, interpretar ou representar ideias, de maneira que os que não sabem venham a saber, os que não entendem venham a 
compreender e discernir, e os não qualificados tornem-se qualificados. Portanto, o ensino necessariamente começa com o professor entendendo o que deve ser aprendido e como deve ser ensinado. [...] $O$ ensino deve ser adequadamente entendido como algo mais do que a melhoria da compreensão; mas, se não for nem mesmo isso, então serão discutíveis as questões relacionadas ao desempenho de suas outras funções. (SHULMAN, 2014. $p$. 215).

Johnstone (2011) propõe que a química trabalha com os níveis macroscópico, submicroscópico e simbólico. Com esta compreensão é possível o entendimento pedagógico para que ocorra o desejado saber para ensinar química. Por meio destes níveis é possível traçar uma linha didática a ser desenvolvida:

\footnotetext{
Johnstone argumenta que grande parte das dificuldades da aprendizagem em Química se deve ao fato de que, o processo de ensino e aprendizagem, se dá quase que exclusivamente em apenas um dos vértices do triângulo (macroscópico e simbólico), deixando de lado aspectos mais estruturais (correspondente ao vértice do submicroscópico) privando o aluno da sua capacidade de modelagem. Existe uma tendência dos alunos para explicarem os fenômenos químicos no plano macroscópico, pois dificilmente possuem competências ou de recursos simbólicos, no plano mental, para compreensão das transformações químicas num nível que requer uma maior capacidade de abstração como é o caso do nível submicroscópico. (WARTHA, REZENDE, 2011. p. 278).
}

Neste contexto destacamos também a análise elaborada por Santos et al. (2015), com uma classificação dos ODAs alinhada aos aspectos químicos. São destacados os Objetos de Simulação e Modelagem, Jogos Pedagógicos, Objeto de Prática e Objeto de Simulação.

\section{Procedimento metodológico}

A importância da utilização de tecnologia no ensino é inquestionável e precisa ser muito bem trabalhada. Para utilizar os Objetos Digitais de Aprendizagem (ODA) como prática pedagógica é necessário que seja feita uma análise metodológica para agregar conhecimentos e alicerçar o ensino.

Por isso, foi aplicada uma atividade avaliativa aos alunos do curso de Licenciatura em Química da Unimes Virtual que teve como objetivo fazer com que estes refletissem sobre como utilizar, classificar (segundo Santos et al., 2015) e selecionar os aspectos do conhecimento químico (segundo Johnstone, 2000) dos ODAs. Também foi solicitado que os alunos determinassem as competências e habilidades que estes conteúdos desenvolvem, conforme os PCN+ Ensino Médio.

Destacamos nesta atividade a análise de dois ODAs cujos conteúdos consideramos fundamentais uma vez que são de difícil compreensão por se tratar de uma visão microscópica, seja para os alunos do Ensino Médio seja para licenciandos. Atualmente existem alguns repositórios que podem ser utilizados com facilidade. Foram 
selecionados objetos em formato HTML5 que podem ser utilizados em computadores, tablets, iPhones, celulares com sistema Android sem a necessidade de baixar programas específicos. Os alunos deveriam manusear os ODAs e posteriormente realizar um estudo sobre os mesmos.

\section{Apresentação e discussão dos resultados}

$\mathrm{Na}$ atividade avaliativa alvo deste trabalho foi solicitado que os alunos manuseassem os ODAs que abordam os conteúdos "Estados físicos da Matéria" e "Ácidos e Bases" se atendo às possibilidades apresentadas pelos objetos que se relacionavam com 0 conteúdo e que poderiam ser utilizadas para auxiliar na compreensão dos temas.

Foi destacada a importância de que todo trabalho desenvolvido em sala de aula no ensino médio tem que estar alinhado com os Parâmetros Curriculares Nacionais. No nosso caso, mais especificamente, com os PCN+ Ensino Médio, publicados em 2002. Desta forma é possível definir os objetivos a serem atingidos, bem como determinar as competências e habilidades que devem ser desenvolvidas nas atividades propostas.

Posteriormente os alunos deveriam classificar os dois ODAs destacando os aspectos do conhecimento químico. Foi indicado como material de apoio o artigo "Experimentação em EaD: seleção de objetos digitais de aprendizagem e a conexão com a natureza do pensamento químico" (SANTOS et al., 2015).

\subsection{Explanação dos ODAs}

\subsubsection{Estado físico da matéria}

Classificação: Objeto de Prática e Objeto de simulação

Níveis trabalhados: macroscópico, submicroscópico e simbólico

No início da maioria dos cursos de química este conteúdo é abordado, sendo a base para o entendimento de vários aspectos a serem estudados e aprofundados. Muitas vezes foca-se somente na influência da temperatura na mudança dos estados físicos da matéria, sem o devido destaque à pressão e às forças intermoleculares. Desta forma, os alunos não conseguem compreender o porquê das pequenas variações da temperatura quando em locais com diferentes pressões atmosféricas. Também não fazem a correta relação do porquê a água, uma molécula com pequena massa molecular, tem suas temperaturas tão discrepantes das moléculas com características parecidas. 
Neste ODA, a questão da variação de temperatura, pressão e concentração podem ser compreendidas e simuladas. Na Figura 1 vemos o estágio "States" (1) onde pode-se simular a variação de temperatura (2) trabalhando com três substâncias diferentes (3) e nos três estados físicos (4).

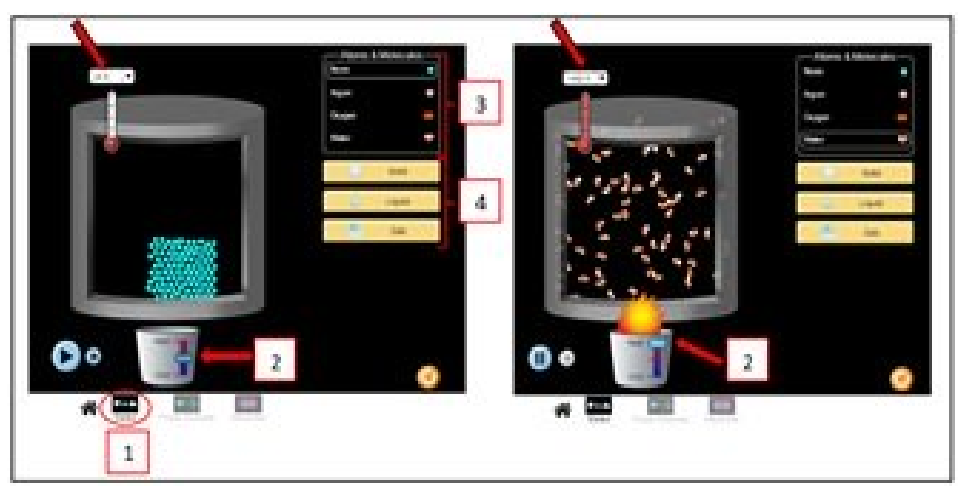

Figura 1. Tela do estágio "States" do ODA Estado físico da matéria

Tem-se, no estágio "Phase Changes" (1), a possibilidade de trabalhar a variação de pressão (2), concentração (3), potencial de interação (4) e diagrama de fases (5) além da temperatura, como pode-se observar na Figura 2.

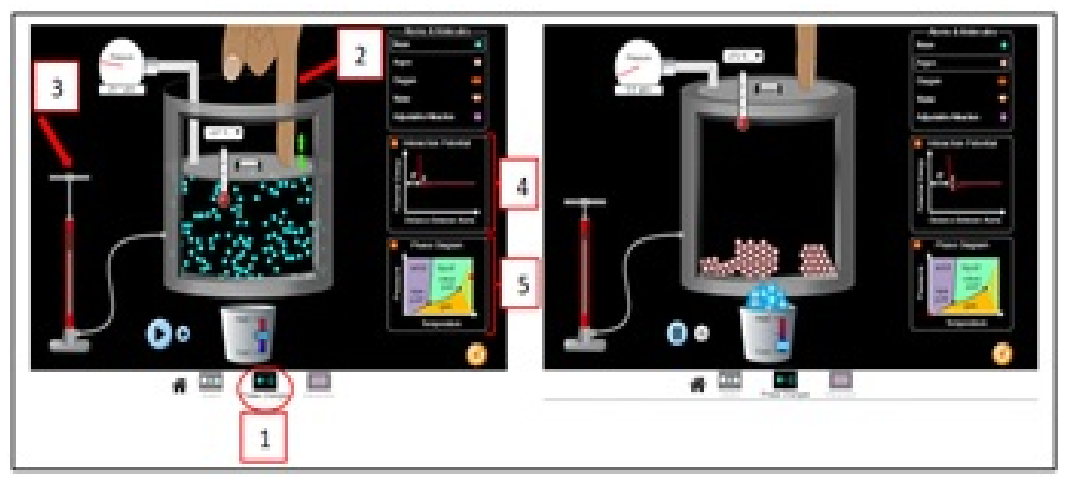

Figura 2. Tela do estágio "Phase Changes" do ODA Estado físico da matéria

\subsection{2. Ácidos e bases}

Classificação: Objeto de Prática e Objeto de simulação

Níveis trabalhados: microscópico

Na ODA Ácidos e Bases Soluções são disponibilizadas duas situações: Introduction e My Solution. Em ambas são abordadas as concentrações de ácidos e bases bem como a condutividade elétrica. Estes não são conteúdos de fácil pois abordam aspectos 
microscópicos e complexos.

Não é raro encontrarmos alunos que através do senso comum associam os ácidos a substâncias que queimam e causam males ao ser humano e ao meio ambiente. As bases também podem ser corrosivas e podem causar danos à pele e ao meio ambiente, dependendo de sua força. Estas substâncias são muito associadas aos antiácidos, mas sem a compreensão da reação que ocorre. Por que algumas substâncias ácidas ou básicas fazem um circuito elétrico acender ou não? Todas estas questões podem ser trabalhadas e melhor assimiladas com a utilização deste ODA.

Existem diferentes formas de visualização, tipos de medição e soluções que podem ser estudadas e analisadas, como demonstrado na Figura 3, na qual identifica-se os seguintes itens: (1) - Estágios do ODA: Introduction (variação do tipo de solução e visualização de molécula ou gráfico) e My Solution (todas as opções de variações anteriores, além do estudo da concentração em mol por litro). (2) - pH da solução ou força dos ácidos ou bases conforme selecionado nos itens 4 e 6. (3) - Equação química balanceada. (4) - Seleção da solução (ácidos fortes/fracos e bases fortes/fracas). (5) Escolha da visualização (solução ou gráfico).

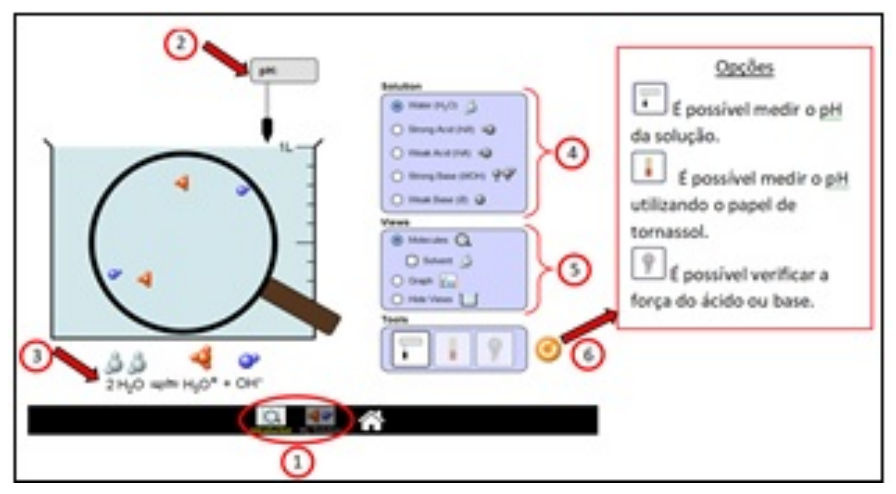

Figura 3. Variáveis possíveis no uso do ODA Ácidos e Bases Soluções

Como no estágio My Solution os alunos podem estudar a concentração em mol por litro, é necessário ter em mente a relação entre duas variáveis e trabalhando com este recurso esta relação fica visível na forma das moléculas, numérica, dos ácidos e das bases, como abordado na Figura 4. 


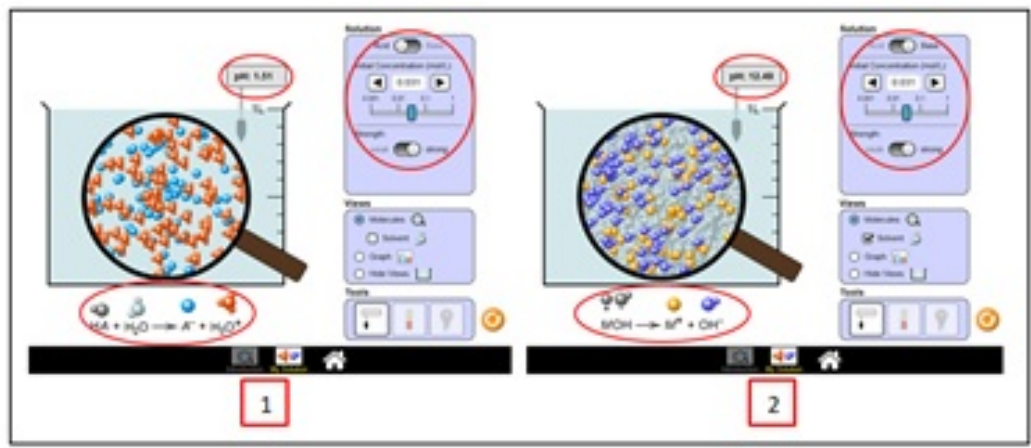

Figura 4. Visualização do estágio My Solution do ODA Ácidos e Bases Soluções

Por fim, na Figura 5 pode-se verificar os gráficos que relacionam as concentrações, o equilíbrio, a força e o pH dos ácidos e bases.

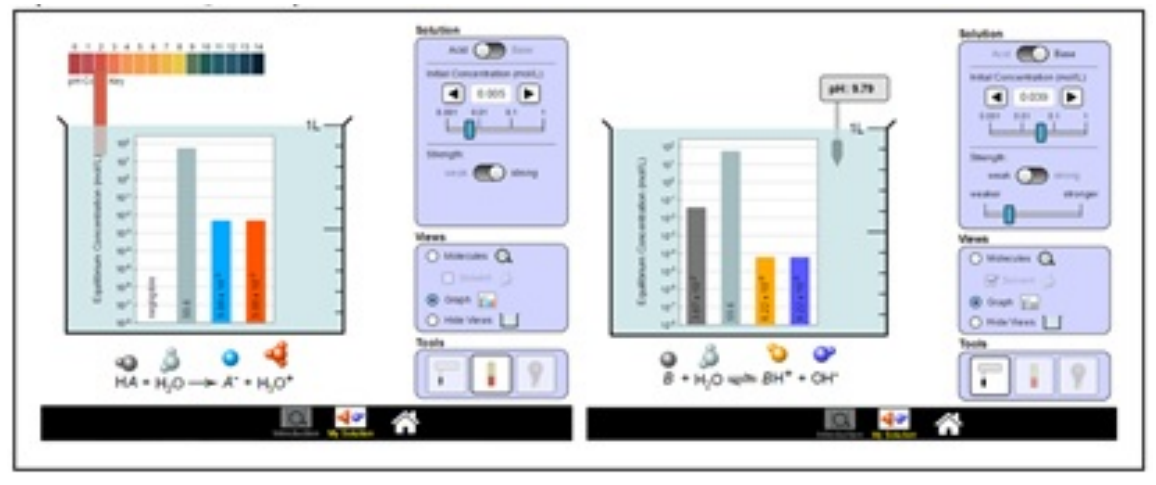

Figura 5. Tela com os gráficos no ODA Ácidos e Bases Soluções

\subsection{Resultados}

Por meio da análise dos trabalhos apresentados os alunos não tiveram dificuldade no manuseio dos ODAs e no entendimento dos conteúdos específicos. Entretanto, com relação às classificações, objetivos, competências e habilidades que estão relacionadas à fundamentação da escolha deste recurso os alunos demonstraram certa dificuldade. Isto ficou retratado nas notas obtidas pela turma objeto desta pesquisa, já que menos da metade dos alunos (45,2\%) obteve a nota máxima, e 54,8\% não conseguiu atingir todos os objetivos da atividade.

Ficou claro que os alunos apresentaram dificuldade na leitura e interpretação do artigo científico e não possuem afinidade em manusear os PCN+. Estes são abordados em diferentes componentes curriculares e em diversas atividades ao longo do curso, entretanto, a maioria dos alunos não domina a capacidade de selecionar objetivos de aprendizagem e traçar as competências e habilidades a serem desenvolvidas. 


\section{Considerações Finais}

Diante dos resultados e análise da atividade constatou-se que a seleção de diferentes recursos pedagógicos esbarra na dificuldade que os alunos possuem para relacionar os recursos com os conteúdos, estabelecendo os objetivos, competências, habilidades e a importância da utilização de um ou outro recurso.

A tecnologia está presente e os alunos a manuseiam com facilidade, mas inseri-la como recurso pedagógico de forma comprometida com o aprendizado já está distante dos futuros professores. Desta forma, a inclusão de atividades com licenciandos que os façam refletir e incentivem o uso de recursos tecnológicos em suas futuras práticas docentes se mostra de grande valia.

\section{Referências Bibliográficas}

BATES, A. W. (Tony). Educar na era digital: Design, ensino e aprendizagem. São Paulo: Artesanato Educacional, 2016.

FIGUEIREDO, A. de C. Saberes e concepções de Educação Algébrica em um curso de licenciatura em Matemática. São Paulo: PUCSP, 2007. 290 p. Tese - Doutorado em Educação Matemática - Pontifícia Universidade Católica de São Paulo, São Paulo, 2007.

JOHNSTONE, A. H. The Development of chemistry teaching: A changing response to changing demand. Journal of Chemical Education, n. 70, 701-704, 1993.

PhET Interactiv Simulations. Using PhET Interactive Simulations in Homework. University of Colorado Boulder. Disponível em: $<$ https://phet.colorado.edu/files/guides/UG-Guide-HW_en.pdf>. Acesso em: 23 jan. 2018. RIBEIRO, A. J. Equação e Conhecimento Matemático para o Ensino: relações e potencialidades para a Educação Matemática. Bolema, Rio Claro (SP), v. 26, n. 42B, p. 535-557, abr. 2012.

SANTOS, A.L.B.S. et al. Experimentação em EaD: seleção de objetos digitais de aprendizagem e a conexão com a natureza do pensamento químico. 2015. 210 Congresso Internacional ABED de Educação a Distância. Disponível em: $<$ http://www.abed.org.br/congresso2015/anais/pdf/BD_130.pdf>. Acesso em: 18 abr. 2018.

SANTOS, M. E. K. L.; AMARAL, L. H. Avaliação de objetos virtuais de aprendizagem no Ensino de Matemática. REnCiMa, v.3, n.2, p. 83-93, jul/dez 2012.

SHULMAN, L. S. Conhecimento e ensino: fundamentos para a nova reforma. Trad. e Leda Beck e revisão técnica de Paula Louzano. Cadernoscenpec - São Paulo | v.4 | n.2 | p.196-229 | dez. 2014. 
SOUZA, A. A. N.; SCHNEIDER, H. N. Tecnologias digitais na formação inicial docente: articulações e reflexões com uso de redes sociais. ETD - Educ. Temat. Digit. Campinas, SP v.18 n.2 p. 418-436 abr./jun.2016.

WARTHA, E. J.; REZENDE, D. de B. Os níveis de representação no ensino de química e as categorias da semiótica de Peirce. Investigações em Ensino de Ciências - V16(2), p. 275-290, 2011. 